Ichiei Narita $\cdot$ Shin Goto $\cdot$ Noriko Saito

Minoru Sakatsume · Song Jin • Kentaro Omori

Fumitake Gejyo

\title{
Genetic polymorphisms in the promoter and 5' UTR region of the Fc $\alpha$ receptor (CD89) are not associated with a risk of IgA nephropathy
}

Received: July 17, 2001 / Accepted: August 29, 2001

\begin{abstract}
The molecular mechanisms of immunoglobulin A glomerulonephritis (IgAN), the most prevalent form of primary glomerulonephritis, remain poorly understood. Recently, the essential role of soluble Fc $\alpha$ receptor (Fc $\alpha$ R) in the formation of the pathogenic immune complex has been revealed. We screened genomic DNA samples from patients with IgAN and those with other glomerular diseases for polymorphisms in the promoter and the 5'untranslated region region of the $F c \alpha R$ gene by direct nucleotide sequencing. We found three common polymorphisms in this region, $\mathrm{T}-114 \mathrm{C}, \mathrm{T}-27 \mathrm{C}$, and $\mathrm{T}+56 \mathrm{C}$ from the putative transcription initiation site. Each genotype was determined in 151 patients with IgAN and 163 patients with other glomerular diseases shown to have no mesangial IgA deposition by renal biopsy. The haplotype analysis revealed tight linkage disequilibrium among them. An association study for the genotype, allele, and haplotype frequencies of the polymorphisms between the patients with histologically proven IgAN and those with other glomerular diseases showed no significant difference in the genotype, allele, and haplotype distributions between the two groups. The present study indicates that the analyzed polymorphisms of the $F c \alpha R$ gene do not appear to be primarily involved in the susceptibility to IgAN.
\end{abstract}

Key words IgA nephropathy · Fc $\alpha$ receptor · Gene polymorphism $\cdot$ Haplotype $\cdot$ Promoter $\cdot 5^{\prime}$-UTR region

I. Narita $(\bowtie) \cdot$ S. Goto $\cdot$ N. Saito $\cdot$ M. Sakatsume $\cdot$ S. Jin $\cdot$

K. Omori · F. Gejyo

Division of Clinical Nephrology and Rheumatology, Niigata

University Graduate School of Medical and Dental Sciences, 1-757

Asahimachi-dori, Niigata 951-8510, Japan

Tel. +81-25-227-2193; Fax +81-25-227-0775

e-mail: naritai@med.niigata-u.ac.jp

\section{Introduction}

Immunoglobulin A glomerulonephritis (IgAN) is the most common form of primary glomerulonephritis throughout the world. The disease has a variable clinical course, and one third of patients with IgAN progress to end-stage renal failure within 10-20 years of onset. IgAN is characterized by deposition of mainly polymeric IgA1 in the mesangial area, often associated with higher serum IgA1 levels. Abnormalities in the production and/or catabolism of $\operatorname{IgA}$ are thought to play an important role in the etiology and pathogenesis of IgAN. However, the molecular mechanisms of the disease remain poorly understood. Accumulating evidence suggests that genetic factors determine the susceptibility of developing IgAN (Scolari et al. 1999; Hsu et al. 2000).

Much evidence suggests that primary IgAN is an immune complex-mediated disease. An essential role for soluble $\mathrm{Fc}_{\mathrm{c}} \alpha$ receptor $(\mathrm{F} c \alpha \mathrm{R})$ in the pathogenesis of $\operatorname{Ig} \mathrm{AN}$ has been reported (Launay et al. 2000). It was deduced that the interaction between polymeric $\operatorname{IgA}$ and CD89 $(\mathrm{Fc} \alpha \mathrm{R})$ results in the release of pathogenic soluble CD89IgA complexes. Recently, it has been reported that singlenucleotide polymorphisms (SNPs) exist in the promoter region of the $F c \alpha R$ gene and that these SNPs are associated with the transcriptional or promoter activity of the gene (Shimokawa et al. 2000). Moreover, gene expression of the Fc $\alpha R$ and the FcR $\gamma$ chain (a signaling subunit of FcR), has been shown to be present in human mesangial cells (Gomez-Guerrero et al. 1996). On the other hand, the expression of Fc $\alpha \mathrm{R}$ in blood cells is down-regulated in IgAN patients (Grossetete et al. 1998). Although the mechanism of $\operatorname{IgA}$ deposition in renal mesangium is poorly understood, it seems reasonable to hypothesize that an abnormality in the regulation of FcaR expression may be involved in the pathogenesis of IgAN.

We screened the nucleotide sequence of the $5^{\prime}$ untranslated region (UTR) in the $F c \alpha R$ gene and identified three common polymorphisms. We also examined the possible association between the genetic polymorphisms in 
this region and the susceptibility to $\operatorname{IgAN}$ in Japanese patients.

\section{Subjects and methods}

\section{Subjects}

The protocol for the study was approved by the ethics committee of the institution involved, and informed consent for the genetic studies was obtained from all participants. Genomic DNA of peripheral blood cells was isolated by an automatic DNA isolation system (NA-1000, Kurabo, Osaka, Japan) from 314 individuals, including 151 histologically confirmed IgAN patients. Patients with HenochSchönlein purpura and secondary IgAN, such as hepatic glomerulosclerosis, were excluded from the analysis. The other 163 patients with renal disease were histologically confirmed to have no mesangial IgA deposition, including 45 patients with mesangial proliferative glomerulonephritis without mesangial IgA deposition, 32 with membranous nephropathy, 19 with minor glomerular abnormality, 9 with mesangioproliferative glomerulonephritis, 8 with thin basement membrane disease, 6 with nephrosclerosis, 4 with focal segmental glomerulonephritis, and 40 with other renal diseases (diabetic nephropathy, donor for kidney transplantation, primary amyloidosis, and Alport syndrome).

Diagnosis of IgAN was based on a kidney biopsy that revealed the presence of dominant or codominant glomerular mesangial deposition of IgA as assessed by immunofluorescence examination.

\section{Sequencing of DNA}

A 934-bp fragment containing the 5'-flanking region and the protein-coding sequence for exon 1 of FcaR was amplified by polymerase chain reaction (PCR) based on the published sequence (GenBank accession number X87767). Primers were 5'-CAAACCCCCATGACACAAGT-3', and 5'-CTCCTG TGTCTTGGTGAGTT-3' (Fig. 1, P1 and $\mathrm{P} 2$, respectively). PCR reactions were performed in a $50-\mu \mathrm{l}$ reaction mixture containing $100 \mathrm{ng}$ genomic DNA, $10 \mathrm{pM}$ of each primer, $0.2 \mathrm{mM}$ deoxynucleotide triphosphates
(ddNTPs), $1.5 \mathrm{mM} \mathrm{MgCl}_{2}$, and $1 \mathrm{u}$ Taq DNA polymerase (Takara, Kyoto, Japan) in PCR buffer. The PCR amplification reaction consisted of a cycle at $94^{\circ} \mathrm{C}$ for $5 \mathrm{~min}$, followed by 35 cycles of denaturation at $93^{\circ} \mathrm{C}$ for $30 \mathrm{~s}$, annealing at $63^{\circ} \mathrm{C}$ for $30 \mathrm{~s}$, and extension at $72^{\circ} \mathrm{C}$ for $2 \mathrm{~min}$.

To screen for the existence of common polymorphic sites in the promoter and 5' UTR region of the FcaR gene, we performed direct sequencing of the PCR products from 24 individuals (12 with IgAN and 12 with mesangial proliferative glomerulonephritis without IgA deposits) using the Taq DNA polymerase cycle sequence method. A BigDye Terminator Cycle Sequencing FS Kit was used according to the manufacturer's instruction (Perkin-Elmer, Foster City, CA, USA). The same pair of oligonucleotide primers as that for the PCR reaction was used for bidirectional sequencing. An automated DNA sequencer (model ABI PRISM 310, Perkin-Elmer) was used for the analysis.

\section{Determination of the genotypes}

Each genotype was determined by allele-specific oligonucleotide hybridization after PCR amplification. The forward primer and biotin-labeled reverse primer for PCR were 5'-TCATTCGTTTCTCATCTGAAACA-3' and 5'CGCAGAAGTATG AGGACAGAGC-3', respectively (Fig. 1, P3 and P4). The PCR reaction mixture $(25 \mu \mathrm{l})$ contained 50ng of DNA, $5 \mathrm{pM}$ of each oligonucleotide primer, $0.2 \mathrm{mM}$ ddNTPs, $2.5 \mathrm{mM} \mathrm{MgSO}_{4}$, and 1 unit of DNA polymerase (KOD plus, Toyobo, Osaka, Japan) in KOD buffer. The amplification protocols consisted of a cycle at $94^{\circ} \mathrm{C}$ for $5 \mathrm{~min}$, followed by 40 cycles of denaturation at $93^{\circ} \mathrm{C}$ for $30 \mathrm{~s}$, annealing at $60^{\circ} \mathrm{C}$ for $30 \mathrm{~s}$, and extension at $72^{\circ} \mathrm{C}$ for $2 \mathrm{~min}$.

The amplified DNA fragment of $263 \mathrm{bp}$ was denatured with $\mathrm{NaOH}$, and then hybridized with allele-specific capture probes fixed to the bottom of a microtiter plate by agitation for $30 \mathrm{~min}$ at the appropriate temperature, as listed in Table 1. Specific probes for each SNP are also listed in Table 1 (Nihon Bio Service, Asaka, Japan). The wells were washed thoroughly, and then alkaline phosphatase-conjugated streptoavidin added to each, before the plate was incubated at $37^{\circ} \mathrm{C}$ for $15 \mathrm{~min}$ with agitation. After washing each well thoroughly, 4-methoxy-4 (3-phosphatephenyl) spiro (1,2dioxetan 3,2'-adamantane), a substrate for alkaline

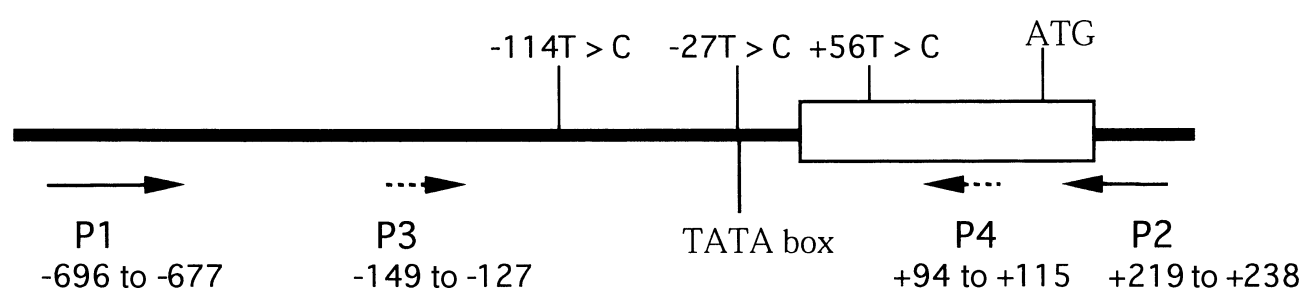

Fig. 1. Partial genomic structure and location of single-nucleotide polymorphisms (SNPs) in the $F c \alpha R$ gene. Exon 1 is represented by an open rectangle, and the promoter and introns are represented by horizontal lines. The numbers indicate the relative position from the putative transcription initiation site. The primers $\mathrm{P} 1$ and $\mathrm{P} 2$ were used for polymerase chain reaction (PCR) direct sequencing, whereas P3 and P4 were used for PCR before allele-specific oligonucleotide hybridization 
Table 1. Nucleotide sequences of the hybridization probes and hybridization temperatures used for allele-specific oligonucleotide hybridization after PCR hybridization

\begin{tabular}{lll}
\hline SNP & Hybridization probe & $\begin{array}{l}\text { Hybridization } \\
\text { temperature } \\
\left({ }^{\circ} \mathrm{C}\right)\end{array}$ \\
\hline T-114C & 5'-TTTTTGAAATA(T/C)AGGTCTTAGGCAGGAG-3' $^{\prime}$ & 57.5 \\
T-27C & 5'-TTTTCCCATCTCTATTTAAAAAAA(T/C)ATACATA-3' $^{\prime}$ & 60.0 \\
T+56C & 5'-TTTTTTCCACTTTG(T/C)TGTGAGGCA-3' $^{\prime}$ & 57.5 \\
\hline
\end{tabular}

PCR, Polymerase chain reaction; SNP, single-nucleotide polymorphism

phosphatase, was added and the luminescence measured by an automated chemiluminescent assay system (Toyobo).

\section{Statistical analysis}

Haplotype frequencies for sets of alleles were estimated using the Estimating Haplotype-frequencies (EH) software program (ftp://linkage.rockefeller.edu/software/eh). All haplotypes below a frequency of $1 / 4 N$, where $N$ is the sample size, were eliminated. Pairwise linkage disequilibrium coefficients were estimated by the maximumlikelihood method and the extent of disequilibrium was expressed as $\mathrm{D}^{\prime}=\mathrm{D} / \mathrm{Dmax}$ or $\mathrm{D} / \mathrm{Dmin}$, according to Thompson et al. (1988).

Statview 5.0 statistical software (SPSS, Inc. Cary, NC, USA) was used for statistical analyses on a Macintosh G4 computer. Chi-square analysis was used when comparing allele and haplotype frequencies between the groups. Hardy-Weinberg equilibrium was tested by a chi-square test with $1 d f$. Values of $P<0.05$ were considered to indicate statistical significance.

\section{Results}

We identified three common SNPs in the promoter and 5'UTR region of the $F c \alpha R$ gene by PCR direct sequencing of 48 alleles from 24 individuals. In addition to two SNPs (C-114T and C+56T), which had already been reported by Shimokawa et al. (2000), we found a T-to-C transition at the -27 nucleotide position from the putative transcription initiation site, which corresponded to the first $\mathrm{T}$ of the TATA box (Fig 1). The genetic polymorphisms we identified contained no restriction sites. Therefore, we used an allelespecific oligonucleotide hybridization method for the genotyping of these SNPs as described in Subjects and Methods. Genotypes in each biallelic sites were clearly defined in all subjects using this method and the results were completely consistent with those of the PCR direct sequencing method.

Genotype and allele frequencies for each polymorphic site in 151 patients with IgAN and in 163 patients with other renal diseases distinct from IgAN are shown in Table 2. The expected frequency of the genotypes, under the assumption of Hardy-Weinberg equilibrium, did not differ from the
Table 2. Genotype and allele frequencies in patients with IgAN and those with other diseases distinct from IgAN

\begin{tabular}{lllll}
\hline Position & Genotype & IgA nephropathy & Others & $P$ value \\
\hline-114 & CC & 11 & 14 & \\
& CT & 69 & 60 & \\
& TT & 71 & 89 & 0.278 \\
-27 & CC & 2 & 3 & \\
& CT & 36 & 29 & \\
& TT & 113 & 131 & 0.401 \\
+56 & CC & 24 & 26 & \\
& CT & 80 & 72 & \\
& TT & 47 & 65 & 0.229 \\
& Total & 151 & 163 & \\
-114 & Allele & & & \\
& C & 0.301 & 0.270 & \\
-27 & T & 0.699 & 0.730 & 0.434 \\
& C & 0.132 & 0.107 & \\
+56 & T & 0.868 & 0.893 & 0.398 \\
& C & 0.424 & 0.380 & \\
& T & 0.576 & 0.620 & 0.304 \\
\hline
\end{tabular}

Table 3. Pairwise linkage disequilibrium coefficients $\left(D^{\prime}\right)$ between SNPs

\begin{tabular}{llll}
\hline & \multicolumn{2}{l}{} & \\
\cline { 2 - 4 } Polymorphism & $\mathrm{C}-114 \mathrm{~T}$ & $\mathrm{C}-27 \mathrm{~T}$ & $\mathrm{C}+56 \mathrm{~T}$ \\
\hline $\mathrm{C}-27 \mathrm{~T}$ & 0.999 & - & - \\
$\mathrm{C}+56 \mathrm{~T}$ & 0.968 & 0.953 & - \\
\hline
\end{tabular}

$P<0.001$ in each pair

SNP, Single-nucleotide polymorphisms

${ }^{a} \mathrm{D}^{\prime}$ was estimated according to Thompson et al. (1988)

observed genotype frequencies in both groups of patients (data not shown). The pairwise linkage disequilibrium between the three SNPs in the promoter and 5' UTR region of the $F c \alpha R$ gene was estimated. Each SNP was in tight linkage disequilibrium with the other (Table $3, P<0.001$ ). The estimated frequencies of each major haplotype in the patients with IgAN and those with other renal diseases are shown in Table 4 . The genotype, allele, and haplotype distributions were compared among patients with IgAN and those with other renal diseases and no significant differences were detected. In addition, there was no difference in the serum $\operatorname{IgA}$ level among each of the genotypes or haplotypes in both the patients with IgAN and those with other glomerulonephritis (data not shown). 
Table 4. Estimated haplotype frequency in patients with IgAN and those with other renal diseases distinct from IgAN

\begin{tabular}{|c|c|c|c|c|}
\hline \multicolumn{3}{|c|}{ Haplotype } & \multirow[b]{2}{*}{ IgA nephropathy } & \multirow[b]{2}{*}{ Others } \\
\hline $\begin{array}{l}\text { Locus } \\
-114\end{array}$ & $\begin{array}{l}\text { Locus } \\
-27\end{array}$ & $\begin{array}{l}\text { Locus } \\
56\end{array}$ & & \\
\hline $\mathrm{C}$ & $\mathrm{T}$ & $\mathrm{C}$ & 0.288 & 0.269 \\
\hline $\mathrm{T}$ & $\mathrm{C}$ & $\mathrm{C}$ & 0.128 & 0.102 \\
\hline $\mathrm{T}$ & $\mathrm{T}$ & $\mathrm{T}$ & 0.568 & 0.614 \\
\hline
\end{tabular}

\section{Discussion}

IgAN is characterized immunohistologically by the deposition of IgA in the renal mesangium. Fc receptors have been considered to play an important role in the pathogenesis of immunoglobulin-mediated inflammations such as allergic diseases. Like other Fc receptors, Fc $\alpha$ R can mediate various inflammatory signals to the cells, indicating the possibility that this receptor is involved in the development of IgAN. In fact, there is accumulating evidence that Fc $\alpha R$ acts as a crucial molecule in the pathogenesis of IgAN. Moreover, the important role of soluble Fc $\alpha \mathrm{R}$ in the formation of the pathological immune complexes is evident in human IgAN and in the mouse model of IgAN (Launay et al. 2000). Thus, $\mathrm{Fc} \alpha \mathrm{R}$ may be the functional candidate for a genetic study to identify susceptibility to IgAN. Polymorphism in the regulatory region for $F c \alpha R$ gene expression is thought to be especially important, because earlier studies reported increased expression of FcaR in patients with IgAN (Kashem et al. 1994; Monteiro et al. 1995; Kashem et al. 1997).

We identified three SNPs in the promoter and 5' UTR region of the $F c \alpha R$ gene, one of which has not been noted in previous reports (Shimokawa et al. 2000). Although the reason for the discrepancy between the previous report and this study is not clear, the presence of SNP C-27T was confirmed by two distinct methods, direct nucleotide sequencing and allele-specific oligonucleotide hybridization, each using different primers and protocols for the PCR reactions.

Our study failed to show any difference of the genotype or allele frequencies in this region between patients with IgAN and those with other types of glomerulonephritis. It is possible that our study population was not large enough to produce statistically significant results. Nonetheless, the numbers of patients with $\operatorname{IgAN}$ and with other types of glomerulonephritis analyzed in this study were much larger than a previous report that showed a significant difference between the genotype and allele distributions of the two groups (Tsuge et al. 2001). The number of subjects with IgAN was 151 in the present study, but only 90 in the previous study. The allele frequencies at position -114 and +56 in the patients with other types of glomerulonephritis were in good accordance with those of the previous report. Therefore, there is a possibility that the finding of the previous report resulted from a potential overfitting caused by the small sample size. The in vitro study of a monocyte cell line demonstrated that the promoter of FcaR, containing both the $-114 \mathrm{C}$ and $+56 \mathrm{C}$ alleles, had a significantly higher promoter activity than that containing both $\mathrm{T}$ alleles at the corresponding sites. However, the frequency of the haplotype $-114 \mathrm{C},-27 \mathrm{~T},+56 \mathrm{C}$, the only major haplotype with both $-114 \mathrm{C}$ and $+56 \mathrm{C}$, was no different between the two groups.

The results of this study indicate that the genetic polymorphism in this region does not possess any direct or major effect on the susceptibility of developing IgAN. However, our study does not exclude the importance of a transcriptional or functional abnormality of the $F c \alpha R$ gene in the pathogenesis of IgAN. Genetic factors, which determine the susceptibility to dysregulation of the $\operatorname{IgA}$ immune system and to the pathogenesis of IgAN, are thought to be heterogeneous. Recently, a genome-wide linkage analysis performed in 30 Caucasian kindred with IgAN revealed a significant linkage of this disease to a 10 -cM locus in 6q2223 , although not all the kindred analyzed were linked to this locus (Gharavi et al. 2000). This may indicate that these genetic factors are heterogeneous. In fact, it has been reported that a polymorphism in the I $\alpha 1$ promoter region, the regulatory region in class switch recombination, possibly causes enhanced IgA production in some, but not all, patients with IgAN (Yano et al. 1998). In addition, many other genetic polymorphisms, for example, specific human leukocyte antigen (HLA) encoded by the major histocompatibility complex (MHC) locus, genes within the Ig heavy chain loci, and T-cell receptor constant $\alpha$ chain gene, have been reported to be associated with IgAN (Fennessy et al. 1996; Demaine et al. 1988; Deenitchina et al. 1999).

A large population-based and genome-wide study is necessary to clarify the genetic factors contributing to the development of IgAN, which would be helpful in understanding the pathogenic mechanism of IgAN.

Acknowledgments This work was supported by a Grant-in-Aid for Scientific Research on Priority Areas (C) "Medical Genome Science" and by a Grant-in-Aid for Scientific Research (C) from the Ministry of Education, Science, Sports and Culture of Japan. We gratefully acknowledge the excellent technical assistance of Naofumi Imai, Satomi Takeuchi, and Keiko Yamagiwa.

\section{References}

Deenitchina SS, Shinozaki M, Hirano T, Ando T, Hirakata H, Kiyohara Y, Katafuchi R, Fujishima M (1999) Association of a T-cell receptor constant $\alpha$ chain gene polymorphism with progression of IgA nephropathy in Japanese patients. Am J Kidney Dis 34:279288

Demaine AG, Rambausek M, Knight JF, Williams DG, Welsh KI, Ritz E (1988) Relation of mesangial IgA glomerulonephritis to polymorphism of immunoglobulin heavy chain switch region. J Clin Invest 81:611-614

Fennessy M, Hitman GA, Moore RH, Metcalfe K, Medcraft J, Sinico RA, Mustonen JT, D'Amico G (1996) $H L A-D Q$ gene polymorphism in primary $\operatorname{IgA}$ nephropathy in three European populations. Kidney Int 49:477-480

Gharavi AG, Yan Y, Scolari F, Schena FP, Frasca GM, Ghiggeri GM, Cooper K, Amoroso A, Viola BF, Battini G, Caridi G, Canova C, Farhi A, Subramanian V, Nelson-Williams C, Woodford S, Julian BA, Wyatt RJ, Lifton RP (2000) IgA nephropathy, the most com- 
mon cause of glomerulonephritis, is linked to 6q22-23. Nat Genet 26:354-357

Gomez-Guerrero C, Duque N, Egido J (1996) Stimulation of $\mathrm{Fc}(\alpha)$ receptors induces tyrosine phosphorylation of phospholipase C- $\gamma(1)$, phosphatidylinositol phosphate hydrolysis, and $\mathrm{Ca} 2+$ mobilization in rat and human mesangial cells. J Immunol 156:4369-4376

Grossetete B, Launay P, Lehuen A, Jungers P, Bach JF, Monteiro RC (1998) Down-regulation of FcaR receptors on blood cells of $\operatorname{IgA}$ nephropathy patients: evidence for a negative regulatory role of serum IgA. Kidney Int 53:1321-1335

Hsu SI, Ramirez SB, Winn MP, Bonventre JV, Owen WF (2000) Evidence for genetic factors in the development and progression of IgA nephropathy. Kidney Int 57:1818-1835

Kashem A, Endoh M, Nomoto Y, Sakai H, Nakazawa H (1994) Fc $\alpha$ R expression on polymorphonuclear leukocyte and superoxide generation in IgA nephropathy. Kidney Int 45:868-875

Kashem A, Endoh M, Yano N, Yamauchi F, Nomoto Y, Sakai H, Kurokawa K (1997) Glomerular Fc $\alpha$ R expression and disease activity in IgA nephropathy. Am J Kidney Dis 30:389-396

Launay P, Grossetete B, Arcos-Fajardo M, Gaudin E, Torres SP, Beaudoin L, Patey-Mariaud de Serre N, Lehuen A, Monteiro RC (2000) Fc $\alpha$ receptor (CD89) mediates the development of immunoglobulin A (IgA) nephropathy (Berger's disease). Evidence for pathogenic soluble receptor-Iga complexes in patients and CD89 transgenic mice. J Exp Med 191:1999-2009

Monteiro RC, Grossetete B, Nguyen AT, Jungers P, Lehuen A (1995) Dysfunctions of $\mathrm{Fc}$ alpha receptors by blood phagocytic cells in IgA nephropathy. Contrib Nephrol 111:116-122

Scolari F, Amoroso A, Savoldi S, Mazzola G, Prati E, Valzorio B, Viola BF, Nicola B, Movilli E, Sandrini M, Campanini M, Maiorca R (1999) Familial clustering of IgA nephropathy: further evidence in an Italian population. Am J of Kidney Dis 33:857-865

Shimokawa T, Tsuge T, Okumura K, Ra C (2000) Identification and characterization of the promotor for the gene encoding the human myeloid IgA Fc receptor (FcaR, CD89). Immunogenetics 51:945954

Thompson E, Deebs S, Walker D, Motulsky A (1988) The detection of linkage disequilibrium between closely linked markers: RFLPs at the AI-CIII apolipoprotein genes. Am J Hum Genet 42:113-124

Tsuge T, Shimokawa T, Horikoshi S, Tomino Y, Ra C (2001) Polymorphism in promotor region of Fca receptor gene in patients with IgA nephropathy. Hum Genet 108:128-133

Yano N, Asakura K, Endoh M, Abe Y, Nomoto Y, Sakai H, Kurokawa $\mathrm{K}$, Tsukamoto H (1998) Polymorphism in the I $\alpha$ germ-line transcript regulatory region and $\operatorname{IgA}$ productivity in patients with $\operatorname{IgA}$ nephropathy. J Immunol 160:4936-4942 